\title{
Formación inicial del maestro y competencia gramatical para su práctica docente
}

\author{
Rafael Jiménez Fernández \\ Universidad de Cádiz (España) \\ Manuel Francisco Romero Oliva \\ Universidad de Cádiz (España) \\ Hugo Heredia Ponce \\ Universidad de Cádiz (España)
}





\title{
Formación inicial del maestro y competencia gramatical para su práctica docente
}

\section{School Teachers Trainees and the Grammatical Competence for their Teaching Practice}

\author{
Rafael Jiménez Fernández \\ Universidad de Cádiz (España) \\ rafael.jimenezfernandez@uca.es \\ Manuel Francisco Romero Oliva
Universidad de Cádiz (España)
manuelfrancisco.romero@uca.es
}

Hugo Heredia Ponce

Universidad de Cádiz (España)

hugo.heredia@uca.es

Fecha de recepción: 17 de septiembre de 2018

Fecha de aceptación: 1 de marzo de 2019

\section{Resumen}

Este trabajo tiene como objetivo comprobar, a partir de un estudio de caso, si los alumnos que acceden a la educación superior (en nuestro caso, futuros maestros de Educación Primaria) demuestran una competencia gramatical elemental que les capacite para afrontar su formación inicial como maestros. A partir de una prueba realizada (cuestionario de dominio gramatical), se ha comprobado que el nivel competencial es bajo y que la variable de estudios de procedencia no es significativa, pues en ambos casos mantienen la falta de dominio gramatical. El estudio se completa con una matriz DAFO que pretende ofrecer líneas de actuación para afrontar esta problemática desde la confluencia de los resultados cuantitativos obtenidos y de las técnicas etnográficas usadas (narrativa biográfica y grupo focal). Palabras claves: Competencia gramatical; Formación inicial; Grado en educación primaria; Diagnóstico; creencias

\section{Abstract}

This paper is focused on checking, as a main objective, if the students who get into higher education show a basic grammatical competence that qualifies them to face their initial training as future teachers (in this case, future Primary School teachers). It has been checked that the level of this competence is awfully low and that the study variable is not meaningful, since the lack of grammatical competence 
remains; those assumptions are based on a grammar skill survey. This study is completed with a SWOT matrix that offers areas of action to solve these problems from the comparison between the quantitative results and the ethnographic techniques used (biographical narrative and focal group)

Keywords: Grammatical Competence; Initial Training; Degree in Primary Education; Diagnosis; Belief.

\section{INTRODUCGIÓN}

Desde siempre la formación inicial de los futuros maestros ha suscitado el análisis y la reflexión de quienes se han venido interesando por el mundo de la educación. Antes y ahora se ha reconocido la importancia de contar con unos docentes bien preparados, con una sólida formación académica y profesional para afrontar con solvencia una enseñanza de calidad. Sin esta condición el sistema educativo difícilmente puede garantizar con éxito dicho objetivo. Nadie duda de los esfuerzos habidos durante las últimas décadas por parte de las administraciones educativas para conseguir una mejora en la preparación profesional del maestro, si bien no es menos cierto que la formación inicial del magisterio se ha llegado a considerar como deficiente en muchos otros momentos.

No hace falta que nos remontemos más allá del plan de estudios de 1970. Con anterioridad a este año "la formación inicial (nacida pobre y desvalida más de un siglo antes) siempre se consideró de segunda categoría, como una ampliación del bachillerato" (Imbernón, y Colén, 2015, p. 58). Y, efectivamente, así fue. Se trataba de un currículum muy devaluado, en consonancia con una profesión poco prestigiosa que no necesitaba de una gran especialización, de ahí que nunca fuera equiparada con otros estudios de carácter profesional, llegándose incluso a promover en diferentes épocas "la infantilización del conocimiento de los maestros como la mejor formación: hay que ponerse a la altura del niño, no saber más que él (Anguita, 1997, p. 5). Por entonces, y también en la actualidad, ha predominado en el pensamiento de muchas personas que para ser maestro tenía que saberse un poco más que los alumnos (Imbernón y Colén, 2015). Tal visión se veía potenciada por el fácil acceso a las Escuelas de Magisterio y el alejamiento del ámbito académico superior. Como consecuencia de la baja consideración académica de estos estudios así como de la escasa estimación social de la profesión, los alumnos que solían acudir a estos centros procedían de las clases medias agrarias y bajas urbanas (Anguita, 1997).

A partir de que los estudios de magisterio se transformaran en estudios universitarios $^{1}$, los distintos planes de estudio se han visto cuestionados por una intensa revisión crítica procedente de todos los sectores educativos implicados. El propósito no era otro, sino el de aprovechar esta coyuntura favorable, por la que

1 Fue en 1970 cuando los estudios de Magisterio adquieren rango de diplomado universitario, coincidiendo con la promulgación de la Ley General de Educación. Fue entonces cuando las Escuelas Normales pasan a integrarse en la Universidad como Escuelas Universitarias del Profesorado de EGB. 


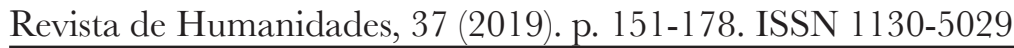

los estudios de magisterio se integraban en el mapa de titulaciones universitarias, para lograr su dignificación y así poder modificar actitudes e ideas adversas muy asentadas a lo largo de la historia de la educación. Todo ello obligaba a realizar un replanteamiento en la formación inicial del profesorado, conforme a la sociedad española de aquella época, inmersa en profundos cambios políticos y económicos, que demandaba una educación de calidad para las nuevas generaciones de estudiantes.

\subsection{La educación lingüística en la formación inicial del maestro}

Desde la constitución de las primeras escuelas normales para formar los maestros primarios hasta finales del siglo pasado, el modelo formativo básico se encontraba asentado sobre tres pilares: cultura general, teoría pedagógica y prácticas docentes. El tema de discusión giraba en torno a la relativa importancia o peso académico que pudieran tener cada uno de esos ámbitos de formación.

Durante las dos décadas que estuvo vigente el Plan de Estudios de 1971, la formación inicial de los futuros profesores contemplaba tres cursos académicos y las siguientes especialidades: Ciencias, Ciencias Humanas, Filología y Preescolar. Con tal estructuración se pretendía que el alumnado de magisterio quedara capacitado para impartir una enseñanza, ya fuese globalizada, con vistas a los Ciclos Inicial y Medio de la EGB, o especializada en un área de conocimiento, con contenidos específicos para atender al Ciclo Superior (segunda etapa de EGB). Se trataba, por tanto, de formar a los futuros docentes de la educación básica bajo dos perfiles difícilmente armonizables: el de generalista y el de especialista; de ahí que el plan contemplara asignaturas comunes, que contribuían a la formación generalista, así como otras más vinculadas a las distintas especialidades, entre ellas las de carácter optativo.

En cuanto al ámbito de la lengua y su enseñanza, todas estas especialidades incorporaban, durante el primer curso de la Diplomatura, una materia sobre lengua española donde los estudiantes universitarios profundizaban en sus conocimientos lingüísticos. Para su especialización en lenguas y literatura contaban con la especialidad denominada Filología, donde cursaban otra asignatura de contenidos de lengua, además de una asignatura sobre didáctica de la lengua, que por vez primera y única se ofertaba en el itinerario curricular. Ciertamente, se trataba de un plan de estudios con una excesiva presencia de materias lingüísticas en detrimento de otras sobre la didáctica específica de la lengua. Si para el resto de especialidades se garantizaba, al menos, una preparación académica en lengua española, no sucedía lo mismo con respecto a su enseñanza/aprendizaje. Se aseguraba, por tanto, el conocimiento lingüístico en tanto que se dejaba al margen los contenidos didácticos.

Tanto la forzosa especialización que hemos apuntado como el evidente descuido por la preparación profesional fueron dos cuestiones que suscitaron mucha crítica y controversia entre quienes esperaban que se produjera un cambio 
cualitativo en unos estudios que pasaban a integrarse dentro del mapa de titulaciones universitarias.

Con la implantación de la Ley Orgánica de Ordenación General del Sistema Educativo (1990) comienza su andadura un nuevo marco normativo y regulador del sistema educativo español. Para muchos fue un momento ideal para que los estudios de Magisterio se convirtieran en licenciaturas y así poder equiparar la labor profesional de los maestros con la de los profesores de secundaria y bachillerato. De este modo, a juicio de una gran mayoría de educadores, se obtendría el tan ansiado reconocimiento social del que lamentablemente carecían. Se trataba, claro está, de prestigiar dichos estudios con el fin de que la labor profesional del colectivo quedara equiparada por siempre a la de los profesores de secundaria. Sin embargo, las expectativas se frustraron solo por cuestiones económicas y todo permaneció como antes.

Un año después, a partir del Real Decreto 1440/1991, se establecen las directrices generales propias de los planes de estudios conducentes a la obtención del título universitario de Maestro en sus distintas especialidades. Atrás queda el perfil del maestro generalista y también especialista en Ciencias, Ciencias Humanas, Filología y Preescolar, y surge una nueva figura del maestro ahora solo especialista en una de las 7 especialidades ofertadas por la titulación.

Según este Plan de Estudios y en lo que se refiere al área de Didáctica de la Lengua, la propuesta curricular mostraba desaciertos de gran calado. Por un lado, los contenidos lingüístico-didácticos no contaban con el mismo peso de créditos, según de qué especialidad se tratase. Así, en la especialidad de Educación Especial no se contemplaban; en Educación Física y Musical gozaban de escasa importancia, mientras que en el resto de especialidades tales contenidos presentaban más dedicación en créditos troncales, al tiempo que se podía constatar una mayor relevancia de los contenidos de las materias de formación académica sobre cultura básica y didácticas específicas en comparación con las disciplinas del ámbito psicosociopedagógico; por otro lado, en cuanto a nuestro campo de actuación desde la didáctica de la lengua, cabe añadir que tanto la desacertada denominación empleada para referirse a algunas de nuestras materias de contenidos lingüísticodidácticos así como el hecho de que, en la mayoría de los casos, su responsabilidad docente recayera entre el área de Didáctica de la Lengua y Literatura y otras áreas afines como Filología y Lingüística no hizo más que abrir un conflicto institucional entre áreas de conocimiento afines con el objeto de determinar cuál de ellas se haría con el encargo de su impartición. La decisión tomada afectaría inevitablemente a la formación destinada a los estudiantes, los cuales recibirían un mayor o menor conocimiento de la lengua o de su enseñanza dependiendo, en definitiva, del perfil docente del profesorado al que finalmente le fuera asignado el encargo docente.

Consideramos, pues, que la formación inicial de los maestros en educación lingüística durante la vigencia de este plan de estudio estuvo condicionada por las 


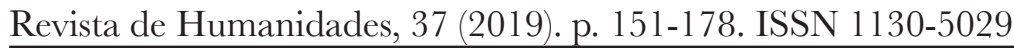

circunstancias político-académicas vividas en cada universidad. El interés por los contenidos lingüístico-didácticos nos parece adecuado en líneas generales, dejando al margen las especialidades de Educación Especial, Musical y Física, y partiendo de la presuposición de que su encargo docente fuera asumido por el área de Didáctica de la Lengua y Literatura. Igualmente estimamos bastante desatinado el establecimiento de un título de Maestro subordinado a una serie de especialidades en perjuicio de la función generalista, consustancial a la preparación curricular de quienes serán los futuros educadores de niños de Infantil y Primaria.

Con la implantación de las nuevas titulaciones de Grados, los estudios universitarios de magisterio alcanzan, por fin, la anhelada ampliación en un año y se decretan dos titulaciones para la habilitación en el ejercicio de la profesión de maestro: el Grado en Educación Infantil y el Grado en Educación Primaria. Ambos grados, con una orientación claramente generalista y creados para afrontar sus respectivas etapas escolares, acabaron con el mapa de especializaciones del sistema educativo anterior. Ahora la especialización, si así puede llegar a llamarse, se reduce solo a las menciones, que se ordenan según criterios muy arbitrarios en virtud de lo que decidieran en cada universidad las comisiones académicas encargadas de planificar estos títulos. Por otra parte, las asignaturas pertenecientes al ámbito lingüístico-didáctico, en el caso de la Universidad de Cádiz, pasan a ser responsabilidad exclusiva del área de didáctica de la lengua y literatura: un logro muy valioso que suponía el reconocimiento hacia un profesorado universitario preparado para asumir las competencias, ya fuesen de carácter lingüístico o didáctico, por su adscripción a dicha área de conocimiento y como filólogos de titulación de procedencia.

Los nuevos grados para el ejercicio de la profesión de Maestro en Educación Infantil y Maestro en Educación Primaria (Orden ECI/3857/2007) presentan una estructura general del plan de estudios donde los créditos se distribuyen entre un módulo de Formación Básica, un módulo obligatorio llamado Formación Didáctico Disciplinar y un módulo para la optatividad ${ }^{2}$. El peso de las materias relacionadas con los conocimientos disciplinares y su enseñanza/aprendizaje o con los aspectos psicopedagógicos y sociales varían proporcionalmente según el grado en cuestión: en Educación Primaria, por ejemplo, el mayor número de créditos corresponde al módulo didáctico disciplinar (100 frente a 60).

Transcurridos ya varios cursos académicos desde la implantación de estas titulaciones para graduados, nos ha permitido comprobar hasta qué punto los alumnos han conseguido los resultados de aprendizaje dispuestos en cada una de las asignaturas de nuestra área, es decir, si estos nuevos diseños curriculares han contribuido o no a la mejora de la formación inicial de nuestros futuros maestros en lo que se refiere al campo de la enseñanza de la lengua. de Grado.

2 No incluimos los créditos de Prácticas Externas ni tampoco los vinculados al Trabajo de Fin 


\subsection{La competencia gramatical}

Realmente, una de las deficiencias más alarmantes a la que nos hemos enfrentado ha sido la escasa competencia lingüística que traen los alumnos que acceden a estos grados: peor en Infantil que en Primaria; pero ambas muy por debajo de lo que debiera ser un nivel competencial acorde con unos estudios superiores. No faltan voces que hacen responsable de esta precariedad formativa al sistema de enseñanza no universitaria existente en nuestro país: poca preparación didáctica de los profesores de Secundaria, desmotivación de alumnado y profesorado, desmesurado academicismo educativo, desatención hacia los contenidos procedimentales, enfoques metodológicos anticuados, etc. A todo ello hemos de añadir las pruebas preuniversitarias de Selectividad, con elevadísimas tasas de aprobados en todos los distritos universitarios y que desde hace muchos años dejó de ser instrumento de selección ("filtro") para el acceso a la enseñanza superior.

Sea lo que fuere, lo cierto es que, al margen de acusaciones y reproches, la baja formación académica en contenidos elementales sobre lengua española de los estudiantes del grado en Educación Primaria es un indicador bastante alarmante que va in crescendo por generaciones de alumnos y todo ello pese a lo que fija la ORDEN ECI/3857/2007 (2007, p. 53748), de 27 de diciembre, por la que se establecen los requisitos para la verificación de los títulos universitarios oficiales que habilitan para el ejercicio de la profesión de Maestro en Educación Primaria donde se dispone que los estudiantes, al finalizar el Grado en Educación Primaria, deberían alcanzar un dominio en español de $\mathrm{C} 1$, de acuerdo con los niveles recogidos en el Marco Común Europeo de Referencia para las Lenguas (Consejo de Europa, 2001).

A partir del conocido término de competencia comunicativa, acuñado por Hymes (1971) dentro del ámbito de la etnografía de la comunicación y entendida como el conjunto de conocimientos y capacidades que el hablante pone en acción para poder comunicarse de manera eficaz en cualquier contexto comunicativo, la concepción de la enseñanza/aprendizaje de lenguas sufre un importante replanteamiento teórico y metodológico. Surge de este modo un nuevo planteamiento teórico que recoge las aportaciones de distintas corrientes científicas del lenguaje centradas en la lengua en uso, tales como la lingüística funcional británica, la sociolingüística americana, la filosofía del lenguaje y muy especialmente la etnografía de la comunicación, y que supone un avance con respecto a la llegada de la competencia lingüística de Chomsky (1965) al campo de adquisición y enseñanza de lenguas. Recuérdese que para el lingüista estadounidense dicha competencia es el conocimiento tácito que tienen interiorizado los hablantes nativos sobre las reglas que gobiernan la estructura abstracta de la lengua, al margen de los factores socioculturales implicados en el uso lingüístico y comunicativo de los individuos. Y fue precisamente este interés del paradigma generativo por el estudio formal de la lengua fuera de la situación comunicativa el aspecto más criticado y contra el que reacciona Hymes, quien aseguraba que el dominio de las reglas gramaticales de una lengua no garantiza por sí 


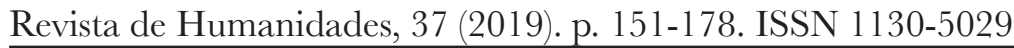

mismo una comunicación eficaz dentro de un contexto sociocultural determinado. Sin embargo, pese a esta mayor atención hacia el proceso de interacción comunicativa, el conocimiento gramatical sigue desempeñando un papel fundamental que no ha de ser desechado ni puesto en tela de juicio para formar a quienes en el futuro serán profesores. En este sentido, cabe mencionar la propuesta teórica desarrollada por Canale y Swain (1980), ampliando la primitiva idea de Hymes, en la que incluyen la competencia lingüística o gramatical como una subcompetencia, entre otras ${ }^{3}$, de la competencia comunicativa, la cual se ocupa del dominio de la gramática, esto es, del funcionamiento del sistema de la lengua.

Queda, pues, demostrado que dentro de este amplio abanico de corrientes del lenguaje que ponen en valor el fenómeno comunicativo en contraste con una concepción inmanentista de la lengua, el conocimiento gramatical cumple su cometido. Si la competencia comunicativa abarca los conocimientos que toda persona necesita para construir mensajes de forma apropiada a la situación comunicativa, será imprescindible contar con el manejo del sistema de reglas que rigen el funcionamiento de cualquier lengua. Esto no supone, evidentemente, una vuelta a postulados ya superados donde solo se hablaba de la importancia de la descripción sistemática de los hechos lingüísticos. Muy al contrario: se trata de aunar bajo la expresión de competencia comunicativa tanto el conocimiento de la lengua como la habilidad para utilizarla adecuadamente en un acontecimiento comunicativo. En consecuencia, estos renovadores planteamientos surgidos a partir de los trabajos de Hymes no están por el abandono del aspecto estrictamente gramatical, sino más bien de acomodarlo dentro de un conjunto de componentes de la competencia comunicativa. En esto mismo incide el Consejo de Europa (2001) cuando, tras definir la competencia gramatical como el conocimiento de los recursos gramaticales de una lengua y la capacidad de utilizarlos, no duda en afirmar que se trata de una capacidad fundamental para el desenvolvimiento comunicativo de los individuos.

Por todo lo anterior, es importante que la formación lingüístico-didáctica de los futuros maestros contemple asignaturas orientadas hacia la actualización y mejora de su competencia gramatical. Quizás, haya quienes se escandalicen de esta propuesta, sobre todo teniendo en cuenta la tendencia de hoy en día de minimizar o

3 Canale y Swain (1980) presentan una primera propuesta taxonómica de la competencia comunicativa, conformada por tres componentes (subcompetencia gramatical, subcompetencia sociolingüística y subcompetencia estratégica) para más tarde ser modificada (Canale, 1983) añadiendo una cuarta subcompetencia, la discursiva. Asimismo, Bachman (1990) realiza una nueva composición partiendo de un modelo sustentado en dos subcompetencias, organizativa y pragmática, dentro de las cuales integra otras más: bajo la primera agrupa las subcompetencias gramatical y textual y bajo la segunda, las subcompetencias ilocutiva y sociolinguistica), si bien esta no sería la disposición definitiva puesto que posteriormente agregaría la subcompetencia estratégica. Por su parte, el Consejo de Europa (2001) se inclina por una clasificación tripartita organizada por las siguientes competencias: lingüística, pragmática y sociolingüística. 
incluso suprimir los contenidos gramaticales durante la educación obligatoria y, por ende, también de los estudios de magisterio. A pesar de todo, es interesante observar ciertos posicionamientos de especialistas en favor de revitalizar la gramática, dada su eficaz contribución en las destrezas comunicativas (composición escrita, expresión oral formal, comprensión lectora) como en determinados aspectos normativos de la lengua (ortografía, corrección gramatical), aparte del beneficio que aporta a la adquisición de otras lenguas y al desarrollo cognitivo.

En el caso de los estudiantes universitarios que cursan el Grado en Educación Primaria, el Departamento responsable de la formación en enseñanza de lenguas luchó por que en los planes de estudios existiera una asignatura enfocada a la mejora de la expresión escrita, habida cuenta de la notoria deficiencia mostrada en este aspecto por el alumnado del grado así como del escaso interés y colaboración del resto de profesorado de áreas no lingüísticas de la Facultad. Pero con el paso de las distintas promociones, desde la puesta en marcha de las nuevas titulaciones, otra considerable insuficiencia se ha sumado a la anterior: la falta de conocimientos gramaticales básicos. Esta circunstancia nos ha exigido disminuir contenidos relacionados con la didáctica específica sobre lengua materna para dar espacio al trabajo de nivelación gramatical del que carecen la mayoría de alumnos matriculados, que llegan a nuestras aulas con una formación gramatical ni siquiera acorde con la etapa de secundaria.

Asistimos, por tanto, a una situación muy preocupante ya que estos alumnos tendrán muchísimas dificultades para enfrentarse a la enseñanza de la gramática ante escolares de Primaria, si ellos mismos desconocen explícitamente las reglas más elementales del funcionamiento de su lengua. Resulta muy complicado preparar profesionalmente a los futuros maestros si no saben dominar unos conocimientos elementales sobre contenidos gramaticales que han de enseñar debidamente a los escolares. Lo deseable sería que los estudios de procedencia contribuyeran a la mejora del manejo formal de la gramática para que de esta manera el profesorado pudiera centrarse en las competencias profesionalizantes. Ciertamente, no perseguimos que nuestros alumnos se conviertan en maestros filólogos especialistas en la ciencia lingüística. Demandamos sencillamente la posesión de unos contenidos básicos sobre la lengua española y, en particular, sobre su componente gramatical.

Es innegable que inicialmente los estudios de magisterio tendieron a acentuar la formación en contenidos científicos y culturales básicos en tanto que se prestaba poca consideración por aquellas otras disciplinas que comportaban un claro sentido profesionalizante. Aprovechar los actuales planes de estudio para corregir viejos desequilibrios disciplinares, esta vez a favor de las didácticas específicas, sería caer en un peligroso efecto pendular que hoy por hoy no tendría sentido dada la imposibilidad de acometer una preparación profesional especializada desde la didáctica de la lengua mientras las nuevas promociones que ingresan en este grado acrediten un pésimo nivel académico en contenidos curriculares sobre lengua española. 


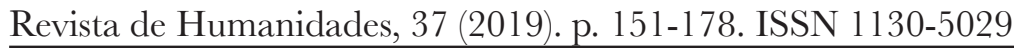

\section{OBJETIVOS Y METODOLOGÍA}

Las bajas tasas de éxito académico obtenidas por los estudiantes del grado en Educación Primaria en las materias sobre didáctica de la lengua, llevaron a un proceso de reflexión entre los docentes de la asignatura que concluyó con la formulación del siguiente objetivo general de nuestro estudio: analizar la competencia gramatical de los maestros en formación de cara a su futura práctica docente.

Partiendo de un paradigma interpretativo en el que el investigador se convierte en el principal activo en la recogida de datos (Colás, 1998, p. 251), indicamos a continuación una serie de objetivos específicos que posibilitarán, mediante la aplicación de diversas técnicas e instrumentos, la comprensión de la situación (Sandín, 2003):

- Objetivo 1: Situar al futuro docente ante un caso de resolución de problemas.

- Objetivo 2: Conocer el pensamiento de los estudiantes del grado en Educación Primaria en cuanto a su dominio y dificultades sobre la gramática.

- Objetivo 3: Determinar las debilidades y fortalezas así como las amenazas y oportunidades en la formación inicial docente a través de una matriz DAFO, tomando como referencia a los estudiantes del grado en Educación Primaria.

\subsection{Contexto y participantes}

Esta investigación se realizó en la asignatura de Didáctica de la Lengua Materna $\left(1^{\circ}\right.$ curso) perteneciente al plan de estudios de grado en Educación Primaria de la Universidad de Cádiz. El grupo de individuos participantes estuvo formado por 56 estudiantes (28 hombres y 28 mujeres), de los cuales 43 (76.8 \%) procedían de la etapa de Bachillerato (codificados BAC_01 [...]BAC_43) y el resto, $13(23.2 \%)$, de los Ciclos Formativos de Grado Superior de FP (codificados GS_01 [...] GS_13). Puesto que consideramos que los estudios de procedencia podrían determinar el dominio gramatical de los estudiantes seleccionados, decidimos investigarlos como variable de análisis estadístico.

\subsection{Diseño de la investigación}

El paradigma de estudio se corresponde con una investigación cualitativa que intenta describir y analizar las "conductas sociales colectivas e individuales, las opiniones, los pensamientos y las percepciones" (McMillan y Schumacher, 2005, p. 400) de una muestra de alumnos de magisterio, de modo que se pueda obtener una explicación o teoría al problema que posibilite su solución y que, al mismo tiempo, sirva para arbitrar estrategias en busca de la mejora educativa en el marco del EEES. Conforme se corresponde con la aplicación de una metodología de carácter cualitativo, hemos optado por el establecimiento de varios métodos y técnicas de investigación -Tabla 1-: 
Formación inicial del maestro y competencia... - R. Jiménez Fernández y otros

Tabla 1. Métodos, técnicas e instrumentos de la investigación

\begin{tabular}{lcll}
\hline Métodos & Objetivos & Técnicas & Instrumentos \\
\hline a) Estudio de caso evaluativo & 1 & Diagnóstico competencial & Cuestionario \\
\hline \multirow{2}{*}{ b) Etnografía educativa } & 2 & Categorización & Narrativa biográfica \\
\cline { 2 - 4 } & 2 & Entrevista semiestructurada & Grupo focal \\
\hline c) Investigación de diseño & 3 & Categorización & Matriz DAFO \\
\hline
\end{tabular}

Cada método de investigación de la tabla 1 justifica las diferentes actuaciones llevadas a cabo:

a. Como estudio de caso evaluativo (Pérez, 1994), se pretendió interpretar y teorizar respecto al grupo de análisis para la toma de decisiones en torno a los problemas de aprendizajes. Nos centramos en una investigación empírica que estudia un fenómeno contemporáneo dentro de su contexto real, en la que los límites entre el fenómeno y el contexto no son claramente visibles y donde se utilizan distintas fuentes de evidencia.

b. Desde la etnografía educativa se diovoza los auténticos agentes y destinatarios de la investigación: los estudiantes. De esta forma, se indagó en el estudio y descripción de la cultura educativa, de las relaciones que se establecían en el contexto investigado, prestando especial atención a los participantes en los actos educativos así como en sus creencias y opiniones: "describir las diversas perspectivas y actividades de profesores y alumnos con el fin de obtener explicaciones para descubrir patrones de comportamiento" (Latorre, Del Rincón y Arnal, 2005, p. 226).

c. Con la investigación de diseño (del inglés, Educational Design Research) hemos aglutinado todas las estrategias de indagación para "comprender y mejorar la realidad educativa a través de la consideración de contextos naturales en toda su complejidad y del desarrollo y análisis paralelo de un diseño instruccionalespecífico"(Molina, Castro, Molina, Castro,2011,p. 75).

\subsection{Descripción de los instrumentos de la investigación}

\subsubsection{Cuestionario de dominio gramatical}

Esta prueba se compone de 13 ejercicios extraídos de un libro de texto de $6^{\circ}$ de Educación Primaria de la editorial Edelvives ${ }^{4}$ (Anexo 1). La selección de las preguntas fue realizada teniendo en cuenta dos criterios: por un lado, que la representatividad

4 Esta editorial, Edelvives -Proyecto Mundo Agua, Primaria 6 (2009)-, es una de las que tiene más presencia en los centros educativos. Es por esta razón por lo que ha sido tomada como referencia para crear la situación-problema del cuestionario, ya que los futuros maestros pueden encontrarse con ella en los diversos centros donde desarrollen su profesión docente. 
$\underline{\text { Revista de Humanidades, } 37 \text { (2019). p. 151-178. ISSN 1130-5029 }}$

de preguntas por cada unidad del libro fuera en razón de una por unidad; y, por otro, que el nivel de análisis lingüístico se correspondiera con el gramatical (morfología y sintaxis). Asimismo, se incluyeron las siguientes dimensiones de estudio: Dimensión 1: dominio por niveles gramaticales - tabla 2- y Dimensión 2: dominio gramatical según estudios de procedencia (variable "bachillerato y ciclo superior"). El análisis cuantitativo de los datos se efectuó mediante el paquete informático Startical Product and Service Solution (SPSS), versión 22.

Tabla 2. Dimensión 1: dominio por niveles gramaticales

\begin{tabular}{lll}
\hline Ámbito lingüístico & Actuación metalingüística & Ítems del cuestionario \\
\hline \multirow{2}{*}{ Morfología } & Formación & $1,2,3,4,5$ \\
\cline { 2 - 3 } & Categorización & $6,7,8,12$ \\
\hline Sintaxis & Funciones & $9,10,11,13$ \\
\hline
\end{tabular}

\subsubsection{Cuestionario desde la narrativa biográfica}

Siguiendo a Medina y Pérez (2017), hemos tomado como referencia la voz de los estudiantes del grado en Educación Primaria para tratar de dar respuesta a una serie de tópicos generadores sobre los contenidos y procesos de su formación inicial, que les garantice un conocimiento para un ejercicio competente de su labor profesional. El diseño del cuestionario se configuró a partir de una relación de tópicos, a modo de estímulos, de manera que cada estudiante generara su biografía formativa respecto a la concepción de la gramática (tabla 3). Basándonos en Granado y Puig (2015), especificamos cuatro bloques temáticos que se retroalimentan en la interpretación del contexto: influencias, mediante el análisis de sus experiencias sobre la gramática y su aprendizaje en estudios conducentes; sus creencias y actitudes, relacionando las experiencias con las creencias y actitudes hacia la gramática de la lengua, auto-concepto competencial...; su formación, haciéndoles tomar conciencia sobre sus conocimientos, modificación de conductas...; e identidad, conformando su modus docendi durante sus estudios de grado. Para el análisis cualitativo se ha utilizado el software NVivo 12.

Tabla 3. Dimensión 2. Creencias y concepciones de la gramática

\begin{tabular}{|c|c|}
\hline Bloques temáticos & Tópicos generadores de la prueba \\
\hline Influencias & ¿Qué recuerdas de tu etapa escolar de la enseñanza de la gramática? \\
\hline $\begin{array}{l}\text { Creencias y } \\
\text { actitudes }\end{array}$ & $\begin{array}{l}\text { ¿Qué es para ti la gramática? } \\
\text { Escribe las palabras que te sugieren la palabra "gramática". Palabras positivas } \\
\text { Escribe las palabras que te sugieren la palabra "gramática". Palabras negativas }\end{array}$ \\
\hline Formación & $\begin{array}{l}\text { ¿Crees que hay que trabajarla en el aula de primaria? ¿Por qué? } \\
\text { ¿Cómo crees que es tu formación gramatical para afrontar tu práctica como } \\
\text { docente? Justifica tu respuesta }\end{array}$ \\
\hline Identidad & $\begin{array}{l}\text { ¿Consideras que un maestro debe tener formación gramatical para dar clases } \\
\text { en primaria? }\end{array}$ \\
\hline
\end{tabular}




\subsubsection{Grupo focal}

El desarrollo de un grupo focal (Escobar y Bonilla-Jiménez, 2009) facilitó, durante tres encuentros, la oportunidad de reflexionar y discutir sobre los resultados alcanzados en las diferentes pruebas -datos que se convirtieron en preguntas guías en el desarrollo de la conversación e interacción con el grupo-. Para ello, se confeccionó el grupo ( 6 estudiantes del grupo clase: 4 con estudios de procedencia de Bachillerato; y 2 de Ciclo Superior; manteniendo la distribución de género $50 \%$ hombre-mujer), de manera que sus aportaciones pudieran completar y perfilar las diferentes dimensiones de la matriz DAFO.

Tabla 4. Dimensión 3. Coevaluación del grupo focal

\begin{tabular}{ll}
\hline Bloques temáticos & Preguntas guías \\
\hline Debilidades & $\begin{array}{l}\text { Coevaluación de la competencia gramatical a raíz de los resultados de las } \\
\text { pruebas de dominio y de las tasas de éxito académico de la asignatura Didáctica } \\
\text { de la lengua materna. } \\
\text { Contenidos y metodología en la asignatura para su formación como maestros. }\end{array}$ \\
\hline Fortalezas & $\begin{array}{l}\text { Aspectos positivos de la gramática en la formación del docente así como las } \\
\text { estrategias desarrolladas por el equipo docente. }\end{array}$ \\
\hline Amenazas & $\begin{array}{l}\text { Cultura y concepciones previas de los estudiantes desde sus estudios de } \\
\text { procedencia. }\end{array}$ \\
\hline Oportunidades & $\begin{array}{l}\text { Aspectos que consideran que deben incorporarse a la metodología en la } \\
\text { asignatura para su formación. }\end{array}$ \\
\hline
\end{tabular}

\subsubsection{Realización de una matriz DAFO}

A partir de los diferentes testimonios del alumnado -narrativa biográfica y grupo focal- y de las ideas aportadas en otras investigaciones, la matriz DAFO -tabla 5nos permite realizar un diagnóstico ajustado a la situación desde las causas internas y externas. Este punto de referencia aportará soluciones y diseñará estrategias para afrontar la problemática de los bajos niveles competenciales de los estudiantes de magisterio con vistas a su formación inicial.

Tabla 5. Dimensión 4. Matriz DAFO

\begin{tabular}{ll}
\hline Análisis de las causas internas & Análisis de las causas externas \\
\hline Debilidades & Amenazas \\
\hline & \\
\hline Fortalezas & Oportunidades \\
\hline
\end{tabular}




\section{RESULTADOS Y HALLAZGOS}

\subsection{En torno a la competencia gramatical de los estudiantes de magisterio}

El diagnóstico del dominio gramatical refleja unos resultados generales con índices muy bajos en las tres actuaciones metalingüísticas consideradas: formación (1.57), categorización (1.75) y funciones (1.45). En una opción dicotómica (aciertoerror) en el que se establece un intervalo entre el valor 1 (error) y el valor 2 (acierto), la media de la prueba presenta un cómputo global de 1.59.

Los resultados evidencian un nivel competencial que no los habilita para afrontar con garantías la labor docente en lo referido a la enseñanza de la lengua en Educación Primaria, pues no hemos de olvidar el carácter específico de la prueba: ejercicios de gramática seleccionados de un libro de texto cuyos destinatarios son niños de 12 años (nivel educativo de $6 .^{\circ} \mathrm{EPO}$ ); y que, por consiguiente, ya tendrían que haber desarrollado en etapas anteriores a la Educación Superior. Hemos considerado los estudios conducentes como variable de estudio pues partíamos de la creencia de que podrían hallarse diferencias significativas de dominio, esto es, que los estudiantes que procedían de Bachillerato accedían con una preparación gramatical mayor que la que poseían quienes habían cursado Ciclo Superior; sin embargo, tras un contraste de resultados, basado en el porcentaje de tasas de éxito en el porcentaje de respuestas correctas, reveló que no existían diferencias significativas Figura 1.

Tras un análisis detallado de los ítems con menor porcentaje de acierto -figura 1, se observó que estos pertenecían al ámbito lingüístico de la morfología y, en

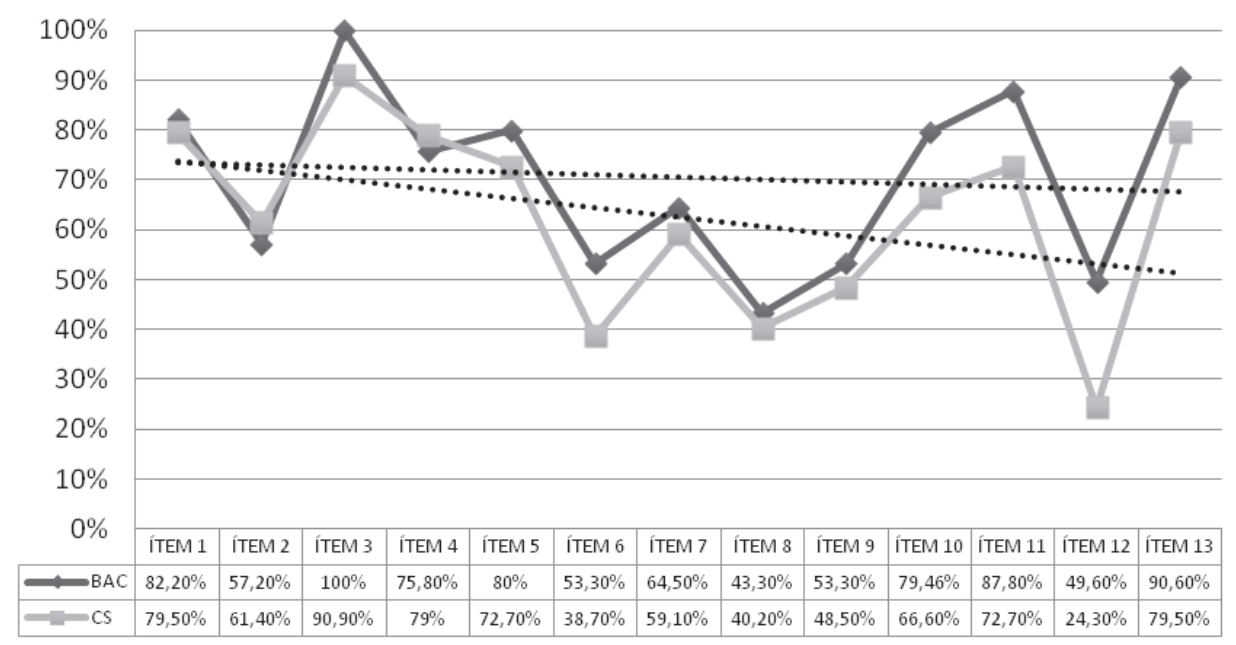

Figura 1. Tasas de éxitos porcentuales de dominio gramatical por estudios de procedencia. 
concreto, a la categorización de palabras (ítems $6,7,8$ y 12), cuyos resultados llegaban a mostrar un dominio preocupante del $40 \%$ (ítem 8) y del $24 \%$ (ítem 12) en los estudiantes de Ciclo Superior; pero la diferencia de dominio no era evidente, como se comprueba en las líneas de tendencias que representan a ambos estudios de procedencia, ya que trazan un área poco diferenciada. Este dato refleja una falta de significación de la variable de estudio entre ambos grupos de estudiantes en el dominio gramatical, que viene constatada en la tabla 6 , ofreciendo únicamente cierta significación en la detección de funciones (sig. 0.043):

Tabla 6. Descriptivos de la actuación metalingüística por variable de estudio de procedencia.

\begin{tabular}{llcccc}
\hline $\begin{array}{l}\text { Actuación } \\
\text { metalingüística }\end{array}$ & $\begin{array}{l}\text { Estudios de } \\
\text { procedencia }\end{array}$ & $\begin{array}{c}\text { Muestra } \\
(\mathbf{N})\end{array}$ & Media & Desviación & Error media \\
\hline Formación & Bachillerato & 43 & 1.5709 & .18684 & .02849 \\
(sig. 0.187) & Grado Superior & 13 & 1.5769 & .24462 & .06785 \\
\hline Categorización & Bachillerato & 43 & 1.7248 & .20047 & .03057 \\
(sig. 0.505) & Grado Superior & 13 & 1.7821 & .16506 & .04578 \\
\hline Funciones & Bachillerato & 43 & 1.3256 & .39163 & .05972 \\
(sig. 0.043) & Grado Superior & 13 & 1.5769 & .49355 & .13689 \\
\hline
\end{tabular}

No obstante, a pesar de que las actuaciones metalingüísticas presentan medias semejantes en los dos grupos de informantes -tabla 6-, se aprecia una mayor dispersión de respuestas en cada una de las dimensiones -figura 2-:
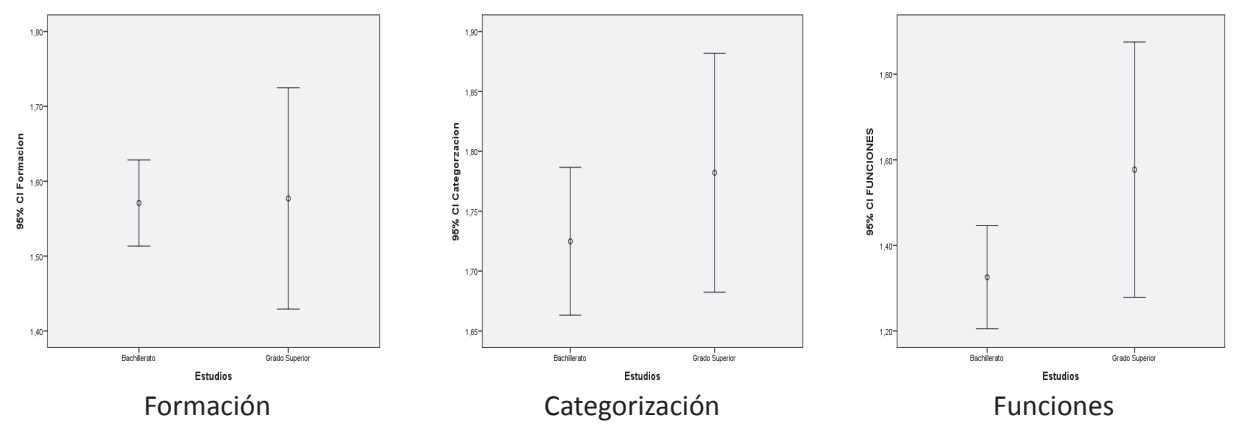

Figura 2: Intervalo de confianza para la media por actuación metalingüística y estudios de procedencia

En efecto, los estudiantes de Grado Superior muestran una mayor dispersión en las respuestas en todas las actuaciones metalingüísticas frente a los que proceden de Bachillerato. Esta diferencia tiene lugar, sobre todo, en las actuaciones de formación de palabras y en el análisis sintáctico (funciones); aproximándose la dispersión en 
$\underline{\text { Revista de Humanidades, } 37 \text { (2019). p. 151-178. ISSN 1130-5029 }}$

la categorización de palabras. Este hecho representa un hallazgo relevante de cara a contemplar la diversidad del aula para su nivelación lingüística, al producirse una mayor pluralidad de niveles en el dominio gramatical de los estudiantes. Y en esa multiplicidad también resulta de interés conocer cuáles son los ejercicios que tuvieron una tasa de éxito mayor y contrastarla con la variable de estudios de acceso -tabla 7-:

Tabla 7. Porcentaje de éxito de ejercicios por ámbito lingüístico y estudios de procedencia.

\begin{tabular}{lccccccl}
\hline \multirow{2}{*}{$\begin{array}{l}\text { Ámbito } \\
\text { lingüístico }\end{array}$} & \multirow{2}{*}{ Ejercicio } & \multicolumn{2}{c}{ Tasa de éxito \% } & \multicolumn{2}{c}{ Tasa de éxito \% } & \multirow{2}{*}{ Ejercicio } & \multirow{2}{*}{ Ámbito } \\
\cline { 3 - 6 } & & Acierto & Error & Acierto & Error & & líístico \\
\hline Formación & 3 & 100 & 0 & 90.9 & 9.1 & 3 & Categorización \\
\hline Funciones & 13 & 90.6 & 9.4 & 79.5 & 20.5 & 13 & Formación \\
\hline Funciones & 11 & 87.8 & 12.2 & 79.5 & 20.5 & 1 & Categorización \\
\hline Formación & 1 & 82.2 & 17.7 & 79 & 21 & 4 & Funciones \\
\hline Formación & 5 & 80 & 20 & 72.7 & 27.3 & 5 & Categorización \\
\hline Funciones & 10 & 79.46 & 20.54 & 72.7 & 27.3 & 11 & Formación \\
\hline Formación & 4 & 75.8 & 24.2 & 66.6 & 23.4 & 10 & Categorización \\
\hline Categorización & 7 & 64.5 & 35.5 & 61.4 & 28.6 & 2 & Funciones \\
\hline Formación & 2 & 57.2 & 42.8 & 59.1 & 40.9 & 7 & Formación \\
\hline Funciones & 9 & 53.3 & 46.7 & 48.5 & 51.5 & 9 & Funciones \\
\hline Categorización & 6 & 53.3 & 46.7 & 40.2 & 59.8 & 8 & Categorización \\
\hline Categorización & 12 & 49.6 & 50.4 & 38.7 & 62.3 & 6 & Funciones \\
\hline Categorización & 8 & 43.3 & 56.7 & 24.3 & 75.7 & 12 & Formación \\
\hline Bachillerato & & & & Ciclo Superior & & \\
\hline
\end{tabular}

Considerando que un dominio adecuado para ejercer de mediador en el aula podría situarse en una tasa de éxito superior al $80 \%$, los resultados manifiestan un bajo dominio pues, si bien en los estudiantes que acceden desde el Bachillerato solo hay 5 ejercicios que superan dicha tasa, mientras que en los de Ciclo Superior solo sucede en uno. Además, atendiendo al ámbito lingüístico, el análisis del dominio de los ejercicios se aglutina en el caso de quienes proceden de Bachillerato (mayor dominio en ejercicios de formación y funciones y con tasas menores en la categorización); sin embargo, entre los resultados de Ciclo Superior, se produce una irregularidad en todas las tendencias de las tasas de éxito, ya que estas vienen representadas en los tres ámbitos lingüísticos y no se encuentra un patrón o tendencia de actuación en ninguno de ellos.

\subsection{Concepciones de la gramática desde la narrativa biográfica}

Las creencias y concepciones, así como la metodología con la que estos futuros docentes aprendieron en la escuela, pueden plantearse como factores influyentes que justifiquen los bajos resultados obtenidos en la prueba de dominio gramatical; 
de ahí la necesidad de dar voz a los sujetos de nuestra investigación a través de sus narrativas biográficas y conocer no solo su identidad, sino también sus influencias docentes (Clandinin y Connelly, 1998). Con esta intención, examinamos las influencias desde los recuerdos de su etapa escolar y sus percepciones sobre la enseñanza de la gramática.

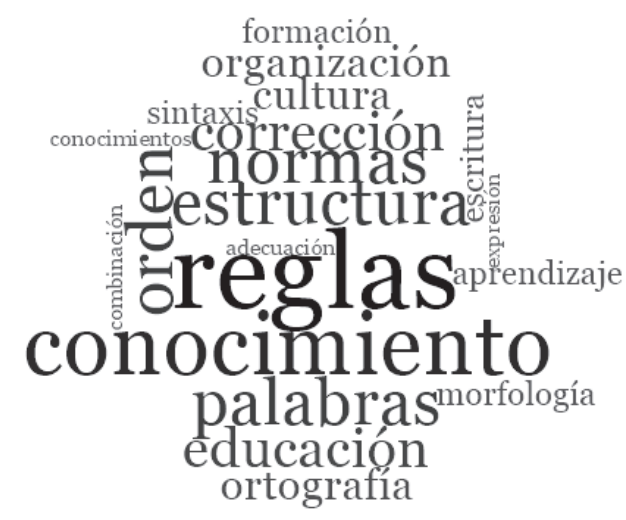

Concepción positiva de la gramática

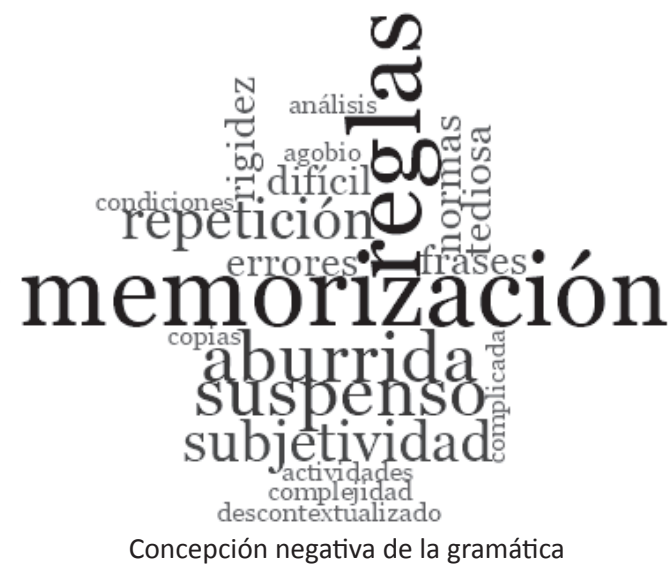

Concepción negativa de la gramática

Figura 3. Conglomerados de palabras

Observamos que, tanto en su concepción positiva como en la negativa, aparecen términos relacionados con el dominio de la lengua desde un enfoque formal frente a uno más comunicativo y de uso. Hay tres términos que destacan en ambas concepciones: por un lado, reglas -que se sitúa en la primera y segunda posición del conteo de los valores positivos (10) y negativos (6), respectivamente- y que vienen apostillados por otros dos términos -conocimiento (8) y memorización (6)- que matizan la evocación del aprendizaje de una gramática con palabras como normas (6), orden (6), estructura (6) o corrección (5). Se recrea un campo asociativo gnoseológico que remite a la concepción de la realidad vivida en la etapa escolar con términos tales como aburrida (4), suspenso (4), repetición (3) o subjetividad (3); todos ellos de un marcado carácter negativo que repercute en una concepción apriorística a la hora de afrontar las asignaturas del área de didáctica de la lengua en el itinerario de su formación inicial.

El estudio de estas concepciones de los futuros maestros conlleva la confección de un mapa jerárquico de nodos con los tópicos referidos a la gramática -figura 4-. El resultado es evidente: el área donde se le consigna un valor al desarrollo de las 
destrezas comunicativas ofrece un conteo muy bajo (1) frente a la preponderancia de la instrumentalización de la enseñanza de la gramática en torno a la realización de ejercicios (12), análisis morfológico (9) y sintáctico (8), así como a la memorización (9) de reglas (6); aspectos que quedan recogidos en testimonios tales como "Hacía muchas actividades en las que se ponía en práctica la gramática y estudiaba memorísticamente algunos aspectos de esta" (BAC_17) o "Recuerdo que eran clases muy sistemáticas, el profesor explicaba lo que se iba a dar en ese día al principio de la clase y luego teníamos que realizar ejercicios sobre ese apartado" (BAC_21); en ellos, como se ve, la gramática se convierte más en un ejercicio filológico sobre el conocimiento del sistema de la lengua que en una estrategia orientada al dominio y mejora de la competencia lingüística mediante la que se aborde el desarrollo de las destrezas comunicativas desde una reflexión en el uso de la lengua: "En mi etapa escolar me explicaron las reglas tanto como para formar palabras como para realizar sintaxis o morfología" (BAC_7).

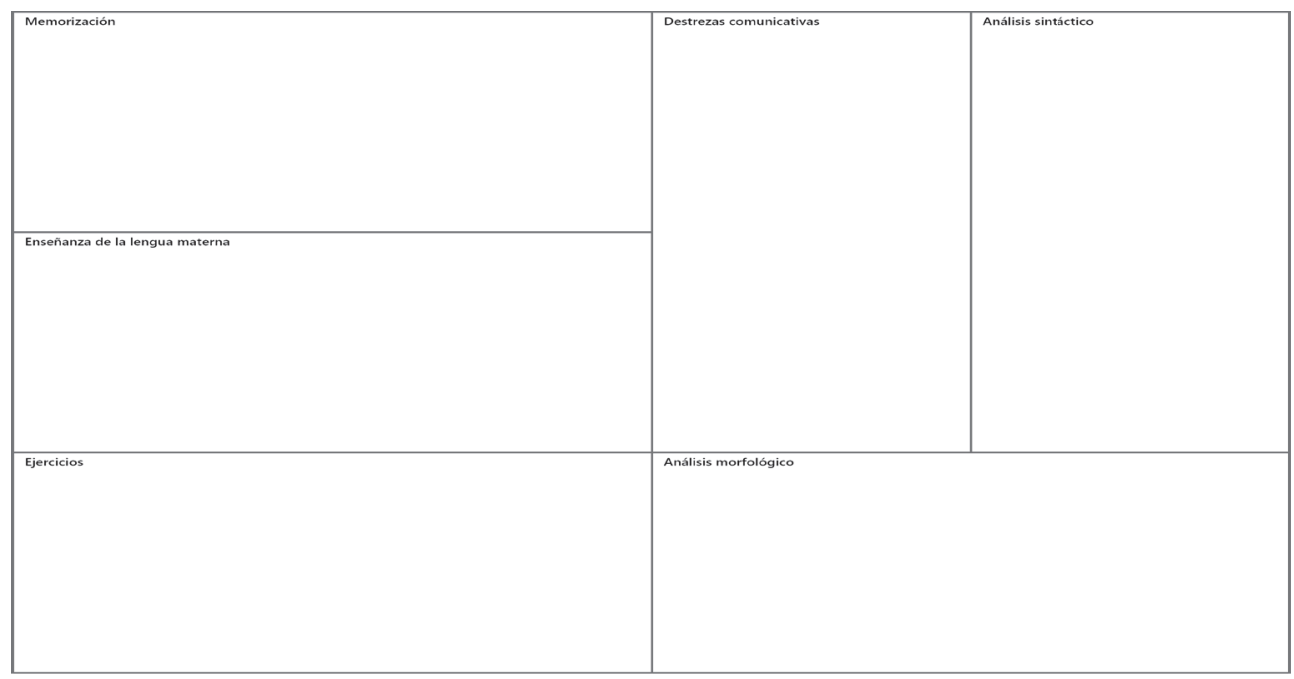

Figura 4. Mapa jerárquico de los tópicos referidos

Este dato aparece verificado en la figura 5 al comprobarse cómo se produce una correlación entre todos los nodos de conglomerados por similitud y también al observarse cómo se correlacionan entre sí creando un universo de relaciones perfectas entre todos los elementos de dicha figura. 


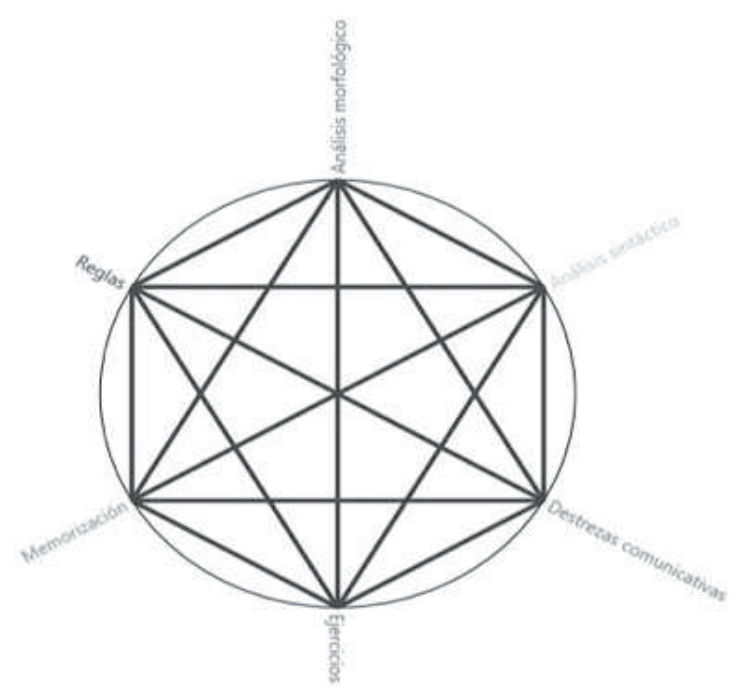

Figura 5. Nodos conglomerados por similitud codificación

Una visión que viene reforzada al comprobarse que la serie de nodos de correlación por conglomerados -tabla 8- presenta un índice con valor máximo en el coeficiente de Jaccard, distribuyendo la similitud entre dos nodos o conjunto de elementos (entre 0 , como valor mínimo, y 1, como máxima similitud). De esta forma, se contempla un conjunto de rutinas de aula que no van más allá de tres actuaciones metalingüísticas: realización de ejercicios basados en el análisis morfológico y sintáctico en donde la memoria juega un papel fundamental.

Tabla 8. Nodos de correlación por conglomerados

\begin{tabular}{llc}
\hline Nodo A & Nodo B & Coeficiente de Jaccard \\
\hline Análisis sintáctico & Análisis morfológico & 1 \\
\hline Destrezas comunicativas & Análisis morfológico & 1 \\
\hline Destrezas comunicativas & Análisis sintáctico & 1 \\
\hline Ejercicios & Análisis morfológico & 1 \\
\hline Ejercicios & Análisis sintáctico & 1 \\
\hline Ejercicios & Destrezas comunicativas & 1 \\
\hline Memorización & Análisis morfológico & 1 \\
\hline Memorización & Análisis sintáctico & 1 \\
\hline Memorización & Destrezas comunicativas & 1 \\
\hline
\end{tabular}

Este panorama justifica las preguntas, a modo de input o impulso motivador, que se plantearon para el desarrollo de sus narrativas biográficas, ya que nos ofrecieron una imagen vinculada a la identidad docente respecto a su formación inicial. Así, fueron muchos los estudiantes que indicaron que su "formación gramatical es insuficiente como para dar clases en cursos superiores, es decir, tercer ciclo de primaria. Además, 


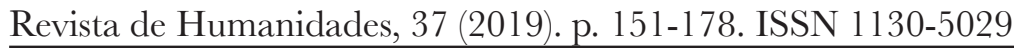

todas las reglas gramaticales las he aprendido de memoria, sin saber el porqué" (BAC_3) y que, por consiguiente, precisaban una formación específica en los estudios de magisterio puesto que "en los libros de texto de Lengua Castellana había ejercicios aislados para trabajar la gramática en particular" (BAC_25).

Tras el análisis de los resultados en esta segunda fase de nuestra investigación, podemos concluir que los estudiantes de magisterio acceden a la universidad con una formación baja en lo que se refiere al conocimiento de su lengua, aunque muchos tengan un autoconcepto muy superior al nivel competencial que ha ofrecido la prueba de dominio gramatical: "Pienso que tengo una buena formación gramatical, pero que aún me faltan muchas palabras por conocer y por conocer su formación” (BAC_22), y que su cultura de aprendizaje escolar tiene un marcado carácter tradicional en el que impera un enfoque formal en la enseñanza de la lengua. Estos aspectos hacen que muchos planteen la necesidad de seguir formándose en los estudios universitarios tanto en el conocimiento de la disciplina como en las estrategias para su enseñanza: "Buena, pero no perfecta, ya que conozco la mayoría de reglas y normas, pero hay otras que no controlo y que debería aprender antes de finalizar la carrera" (BAC_11). Ambas reflexiones nos mueven a pensar en los contenidos que debe ofrecer un itinerario formativo para los maestros generalistas de educación primaria de cara a su práctica docente. Veremos, finalmente, qué nos manifestó el grupo focal en el que participaron algunos participantes de la muestra de estudio y buscaremos centrar sus ideas mediante la realización de una matriz DAFO.

\subsection{Grupo focal}

El grupo focal sirvió para llevar a cabo una coevaluación de los resultados y del contexto formativo: por un lado, desde la visión de los estudiantes, que habían participado en la investigación; y, por otro, desde la de los docentes del departamento, que habían desarrollado el rol de investigadores. En los encuentros se analizaron las diversas dimensiones del estudio y las aportaciones sirvieron para confeccionar la matriz DAFO -tabla 9- que aparecen en las conclusiones de esta investigación.

La puesta en común de los resultados del dominio gramatical (dimensiones 1 y 2) demostró la necesidad de una nivelación lingüística a pesar de que la prueba realizada se correspondiera con niveles muy básicos. Destacan aspectos, reflejados mediante comentarios, que pueden ayudar a comprender la situación. En primer lugar, destaca la propia visión que tienen ellos mismos acerca de su formación gramatical:

"Considerábamos que teníamos una buena formación gramatical hasta que hemos llegado a la carrera y nos hemos encontrado con varias asignaturas y dificultades para superarla; pienso que necesitamos una mayor formación acerca de este tema, ya que para dar clases necesitamos tener las ideas muy claras y aun ese no es mi caso. Conozco aspectos de la gramática como es normal, pero aún tengo muchas dudas" (GF_04) 
Dicha necesidad formativa se agudiza cuando hablamos de los estudiantes cuya procedencia es de Ciclos Superiores:

"En estos momentos, mi formación no es muy adecuada para la práctica docente, pienso que podría mejorar en este aspecto al encontrarme en situaciones que desconozco. Veo diferencias con los que han tenido asignaturas de lengua y literatura en Bachillerato pues han dado más contenidos gramaticales que en yo (en los Ciclos Superiores). Me quedan muy lejos los cursos donde me dieron gramática y tengo que volver a estudiarlo" (GF_06)

En los dos casos, resulta significativo que soliciten una mayor formación específica para la enseñanza de la lengua, en general, y de la gramática, en particular, al considerar que es insuficiente en su formación inicial. Este hecho justifica la necesidad de adaptar los contenidos de las materias del grado o, por lo menos, de replantear la conveniencia de nivelación lingüística desde los docentes que imparten las asignaturas del área:

"La formación que estamos recibiendo es buena, pero a la vez limitada ya que son pocas las horas de gramática que recibo en la facultad y, por ello, nos limita a aprender menos de lo que quisiera" (GF_03)

Además, el cambio en su paradigma docente (ahora pasan a tener la visión de futuros maestros y abandonan el rol de escolares) provocó no solo que tomaran conciencia del bajo dominio gramatical; sino que también, cuando cursaron las asignaturas del área en el grado, vincularon su necesidad formativa a la metodología recibida durante los estudios conducentes a la universidad:

"Muchos compañeros vienen de una formación gramatical que es insuficiente como para dar clases en cursos superiores, es decir, tercer ciclo de primaria. Pues, además, todas las reglas gramaticales las hemos aprendido de memoria, sin saber el porqué" (GF_02)

De este testimonio se desprende un aprendizaje de la gramática descontextualizado donde esta se convierte más en un fin que en un medio para mejorar el comportamiento lingüístico de los estudiantes. Esta idea surgió en varias ocasiones y fue muy relevante en los encuentros con los estudiantes porque evidenció una actitud negativa hacia la materia de lengua -dimensión 3-:

"Cosas negativas, ya que costaba mucho aprenderla y tenía muchos errores gramaticales" (GF_05)

"Desde mi punto de vista bastante negativa, ya que en mi escolaridad no me ayudaron a reforzar esa parte de la lengua. Una vez que llegas a la universidad todos los profesores piensan que debes de saber todo sobre la gramática y puede que más de una persona necesite ayuda" (GF_03) 
Revista de Humanidades, 37 (2019).p. 151-178. ISSN 1130-5029

"Lo recuerdo como un aprendizaje basado en la repetición de actividades muy similares, así como del aprendizaje de reglas gramaticales de forma memorística" (GF_02)

En definitiva, las conclusiones obtenidas del grupo focal abren perspectivas de actuación para hacer frente a la baja competencia gramatical de los futuros maestros en su práctica profesional. Algunas se vinculan tanto a causas externas desde los estudios conducentes como internas desde los itinerarios formativos del grado; sin embargo, no podemos olvidar que la realidad es una y esta debe ser afrontada desde los propios equipos docentes (desde la invocación educativa) y asumida desde los propios estudiantes del grado (desde la nivelación lingüística).

\section{CONCLUSIONES Y DISCUSIONES}

Tras el análisis de los resultados -Dimensiones 1 y $2-$ y, consultados otros estudios acerca de la formación de estudiantes de magisterio, coincidimos con las ideas de Oliva y Acevedo (2005) -centrados, en su caso, en Ciencias Experimentales y su didáctica-, al señalar la necesidad de mejorar el conocimiento de los maestros tanto en las bases lingüísticas y científica de la lengua como en la didáctica específica desde su formación inicial. En España contamos con la problemática de que la formación inicial en didáctica de la lengua y la literatura -al igual que en otras didácticas específicas- tiene dos niveles de actuación y en ambos se produce un desequilibrio entre el conocimiento específico y los aspectos didácticos: por un lado, los estudiantes del máster de profesorado acceden con un elevado nivel epistemológico y demandan más preparación didáctica para acometer con éxito la docencia en los niveles de educación secundaria o bachillerato; y, por otro, los futuros maestros generalistas tienen una mayor formación pedagógica, pero requieren una nivelación mayor de su competencia gramatical que les capacite para la selección de contenidos y convertirlos posteriormente en objeto de aprendizaje desde la concepción de una gramática escolar.

Es por esto por lo que se hace imprescindible un replanteamiento de los contenidos curriculares de los planes de estudio y su adecuación a las necesidades profesionalizantes del alumnado que viene cursando esta titulación. En el caso de los alumnos de magisterio, desde una mayor formación disciplinar, podrán adoptar una actitud más positiva hacia la materia -dimensión 3-, lo que contribuiría a una ruptura con los modelos teóricos, abstractos y memorísticos de la gramática; y, sobre todo, aportaría una gran familiaridad con el diseño de recursos al tiempo que una mayor confianza para impartir tales contenidos.

Reconocemos, por tanto, que la escuela actual exige profesionales que cohesionen la teoría del conocimiento con la práctica educativa y, en este sentido, son las facultades de educación el espacio de donde deben surgir propuestas 
provenientes de la reflexión conjunta de los diferentes agentes implicados en la formación inicial de los maestros. Nuestra aportación se centra en la matriz DAFO resultante del proceso de nuestra investigación -tabla 9- en la que confluyen diversas perspectivas: los resultados del dominio gramatical de los estudiantes del grado en educación primaria (prueba competencial), la voz de los estudiantes (narrativa biográfica y grupos focales), y, por último, la observación y análisis de resultados de los investigadores. Ver Tabla 9.

Los resultados y consideraciones de esta investigación no pretenden ser generalizados al tratarse de un estudio de caso llevado a cabo en la Universidad de Cádiz; sin embargo, consideramos que refleja el sentir de otros profesores que imparten su docencia en diversas universidades españolas. Pretendemos contribuir con ello a una reflexión sobre la necesidad de afrontar una formación de futuros maestros con una sólida capacitación disciplinar y didáctica que sean capaces de asumir el reto de la escuela actual.

Tabla 9. Matriz DAFO

\begin{tabular}{|c|c|}
\hline Análisis de las causas internas & Análisis de las causas externas \\
\hline Debilidades & Amenazas \\
\hline $\begin{array}{l}\text { El aula se convierte en un espacio donde } \\
\text { conviven diferentes niveles de domino gramatical } \\
\text { de estudiantes que acceden desde distintas } \\
\text { titulaciones (Bachillerato y Ciclos Superiores). } \\
\text { Los itinerarios de los grados de magisterio no } \\
\text { ofrecen contenidos epistemológicos que sirvan de } \\
\text { base lingüística a los futuros docentes. } \\
\text { El diagnóstico de la competencia gramatical } \\
\text { evidenció un desconocimiento de contenidos } \\
\text { gramaticales básicos que deben conocer y } \\
\text { dominar para ejercer la docencia. } \\
\text { Las creencias hacia la materia de lengua } \\
\text { manifiestan una actitud negativa arraigada en } \\
\text { el aprendizaje que recibieron en sus estudios } \\
\text { conducentes. }\end{array}$ & $\begin{array}{l}\text { La cultura de aprendizaje de la lengua que } \\
\text { los estudiantes traen adquirida -con un } \\
\text { marcado enfoque formal, memorístico y } \\
\text { descontextualizado- no facilita una actitud hacia } \\
\text { la comprensión de la enseñanza de la gramática } \\
\text { en la escuela y resta confianza para afrontar la } \\
\text { docencia. } \\
\text { Los libros de texto no son una base de referencia } \\
\text { para la reflexión metalingüística y enseñanza } \\
\text { de la gramática (Jiménez, 2011). Es necesario } \\
\text { un replanteamiento didáctico de estos recursos } \\
\text { didácticos para un aprendizaje competencial en } \\
\text { los cursos escolares. }\end{array}$ \\
\hline Fortalezas & Oportunidades \\
\hline $\begin{array}{l}\text { Los procesos de coordinación de las asignaturas } \\
\text { en los grados llega a generar estrategias de } \\
\text { diagnóstico de los estudiantes y facilita planes de } \\
\text { mejora que ayuden a la nivelación de los déficits } \\
\text { encontrados }{ }^{1} \text {. } \\
\text { Desde el Sistema de Garantía de Calidad (SGC) } \\
\text { de los títulos se contempla la valoración del plan } \\
\text { de acogida, tutorización y apoyo la inclusión de } \\
\text { propuestas de actuación ante las necesidades } \\
\text { detectadas en el perfil de ingreso. Estas carencias } \\
\text { se relacionan con el diagnóstico en las asignaturas } \\
\text { y su relación con las tasas de éxito académico. }\end{array}$ & $\begin{array}{l}\text { La existencia de aplicaciones móviles ( } a p p \text { ) y } \\
\text { de plataformas virtuales con materiales para } \\
\text { la nivelación gramatical contribuyen a un } \\
\text { nuevo modelo de aprendizaje autónomo y } \\
\text { autorregulado (m-learning, b-learning...) en } \\
\text { torno al estudiante }{ }^{2} \text {. }\end{array}$ \\
\hline
\end{tabular}


Revista de Humanidades, 37 (2019).p. 151-178. ISSN 1130-5029

\section{BIBLIOGRAFÍA}

Anguita, Rocío (1997). Algunas claves de la historia de la formación del profesorado en España para comprender el presente. Revista Interuniversitaria de formación del profesorado, n. 30, pp. 97-109.

Bachman, Lyle (1990). Habilidad lingüística comunicativa. En Llobera et.al. Competencia comunicativa. Documentos básicos en la enseñanza de lenguas extranjeras. Madrid: Edelsa, pp. 105-129.

Canale, Michael (1983). De la competencia a la pedagogía comunicativa del lenguaje. En Llobera et.al. Competencia comunicativa. Documentos básicos en la enseñanza de lenguas extranjeras. Madrid: Edelsa, pp. 63-83.

Canale, Michael y Swain, Merrill (1980). Theoretical bases of communicative approaches to second language teaching and testing. Applied linguistic, n. 1, pp. 1-47

Chomsky, Noam (1965). Aspect of the Theory of Syntax. Cambrige, Massachusetts: The MIT Press.

Colás, Pilar (1998). La investigación-acción. En Colás, Pilar y Buendía, Leonor Investigación educativa. Sevilla: Ediciones Alfar, pp. 250-260.

Connelly, Michael y Clandinin, Jean. (1998). Stories to live by: Narrative understandings of school reform. Curriculum inquiry, vol. 2, n. 28, pp. 129-162.

Consejo de Europa (2001). Marco Común Europeo de Referencia para las Lenguas: aprendizaje, enseñanza, evaluación. Madrid: Instituto Cervantes-Ministerio de Educación Cultura y Deporte, Anaya. Disponible en: https://bit.ly/1bdmRdq [Consulta: 20 de mayo de 2018].

Escobar, Jazmine y Bonilla-Jiménez, Francy Ivonne. (2009): Grupos focales: una guía conceptual y metodológica. Cuadernos hispanoamericanos de psicología, vol. 9, $\mathrm{n}$. 1, pp. 51-67. Disponible en https://bit.ly/2uEZ6OJ [Consulta: 5 de mayo de 2018].

Granado, Cristina y Puig, María (2015). La identidad lectora de los maestros en formación como componente de su identidad docente. Un estudio de sus autobiografías como lectores. Ocnos, n. 13, pp. 43-63. Disponible en https://bit.ly/2NXxdKK [Consulta: 20 de mayo de 2018].

Hymes, Dell (1971). Acerca de la competencia comunicativa. En Llobera et. al. Competencia comunicativa. Documentos básicos en la enseñanza de lenguas extranjeras. Madrid: Edelsa, pp. 27-47.

Imbernón, Francisco y Colén, M. ${ }^{a}$ Teresa (2015). Los vaivenes de la formación inicial del profesorado. Una reforma siempre inacabada. Tendencias pedagógicas, n. 25, pp. 57-75.

Latorre, Antonio, Del Rincón, Delio y Arnal, Justo (2005). Bases metodológicas de la investigación educativa. Barcelona: Ediciones Experiencias.

McMillan, James H. y Schumacher, Sally (2005). Investigación educativa. Una introducción conceptual. Madrid: Pearson Educación. 
Medina, José Luis y Pérez, M. ${ }^{a}$ José (2017). La construcción del conocimiento en el proceso de aprender a ser profesor: la visión de los protagonistas, Profesorado. Revista de currículum y formación del profesorado, vol. 21, n.1. Disponible en: https://bit.ly/2uHFMjM. [Consulta: 17 de mayo de 2018].

Molina, Marta; Castro, Encarnación; Molina, José y Castro, Enrique (2011). Un acercamiento a la investigación de diseño a través de los experimentos de enseñanza. Enseñanza de las Ciencias, vol. 1 n. 29, pp. 75-88.

Orden ECI/3857/2007, de 27 de diciembre, por la que se establecen los requisitos para la verificación de los titulo universitarios oficiales que habiliten para el ejercicio de la profesión de Maestro en Educación Primaria. Madrid: BOE, n. 312, 2007. Disponible en: https://bit.ly/2LdHCDs [Consulta: 20 de mayo de 2018].

Pérez, Gloria (1994). Investigación cualitativa. Retos e interrogantes. I. Madrid: Editorial La Muralla.

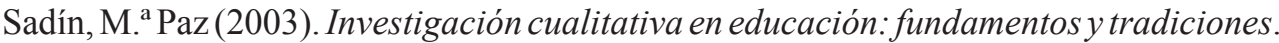
Madrid: McGraw-Hill España. 
Revista de Humanidades, 37 (2019).p. 151-178. ISSN 1130-5029

\section{ANEXO 1}

\begin{tabular}{|c|c|c|}
\hline \multicolumn{3}{|c|}{ APELLIDOS Y NOMBRE } \\
\hline ESTUDIOS & DE ACCESO & REFERENCIA \\
\hline & \multicolumn{2}{|c|}{ PRUEBA DE NIVELACIÓN EN COMPETENCIA GRAMATICAL (morfosintaxis) } \\
\hline ÍTEM 1 & \multicolumn{2}{|c|}{ Cambia estas palabras y escribe las nuevas. } \\
\hline p. 11 & \multicolumn{2}{|c|}{$\begin{array}{l}\text { - yegua > cambia el género y el número } \\
\text { - leyó > cambia el tiempo verbal } \\
\text { - tú > cambia la persona } \\
\text { - aquel > cambia para que indique distancia corta }\end{array}$} \\
\hline ÍTEM 2 & \multicolumn{2}{|c|}{$\begin{array}{l}\text { Copia en tu cuaderno los morfemas de estas palabras, que son flexivos. Ten en cuenta que } \\
\text { algunas tienen más de un morfema. Después, indica si son de género o de número. }\end{array}$} \\
\hline p. 17 & \multicolumn{2}{|c|}{ casas, trenes, señora, perros } \\
\hline ÍTEM 3 & \multicolumn{2}{|c|}{ Señala cuál de las palabras de estos grupos es primitiva y cuáles son derivadas. } \\
\hline p. 33 & \multicolumn{2}{|c|}{$\begin{array}{l}\text { - Arbolado, desarbolar, arboleda, árbol } \\
\text { - Reverdecer, verdor, verde, verdoso } \\
\text { - Friolero, frío, resfriarse, frigorífico } \\
\text { - Papel, traspapelar. Papelón, empapelado }\end{array}$} \\
\hline ÍTEM 4 & \multicolumn{2}{|c|}{ Copia las formas verbales de estas oraciones y separa el lexema de la desinencia o sufijo. } \\
\hline p. 53 & \multicolumn{2}{|c|}{$\begin{array}{l}\text { - El mono trepó a lo alto de su jaula } \\
\text { - Siempre tomo cereales en el desayuno } \\
\text { - En el futuro los robots realizarán muchas de las tareas que hoy hacemos } \\
\text { ¡No miréis directamente al sol! }\end{array}$} \\
\hline ÍTEM 5 & \multicolumn{2}{|c|}{$\begin{array}{l}\text { Copia estos adjetivos y rodea sus sufijos. Después, escribe un nuevo adjetivo con cada uno } \\
\text { de los sufijos. }\end{array}$} \\
\hline p. 65 & \multicolumn{2}{|c|}{$\begin{array}{l}\text { - Ofensivo, creativo, pensativo } \\
\text { - Peatonal, primaveral, genial } \\
\text { - Familiar, pulmonar, lanar } \\
\text { - Ladrador, conmovedor, ganador }\end{array}$} \\
\hline ÍTEM 6 & \multicolumn{2}{|c|}{ Fíjate en el modelo y analiza de la misma manera las siguientes formas verbales } \\
\hline p. 89 & \multicolumn{2}{|c|}{ 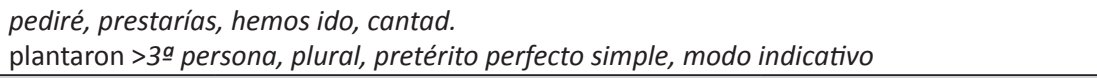 } \\
\hline ÍTEM 7 & \multicolumn{2}{|c|}{$\begin{array}{l}\text { Conjuga el verbo aprender en el tiempo pretérito perfecto simple y pretérito perfecto } \\
\text { compuesto del modo indicativo. }\end{array}$} \\
\hline \multicolumn{3}{|l|}{ p. 105} \\
\hline ÍTEM 8 & \multicolumn{2}{|c|}{$\begin{array}{l}\text { Intenta conjugar estos verbos en } 1 \text { ạ persona del singular del presente de indicativo. A } \\
\text { continuación, di cuáles son verbos completos y cuáles son verbos defectivos. }\end{array}$} \\
\hline p. 121 & \multicolumn{2}{|c|}{ - Abolir, decir, pensar, atañer, balbucir, ver } \\
\hline ÍTEM 9 & \multicolumn{2}{|c|}{$\begin{array}{l}\text { Subraya el predicado de estas oraciones y rodea su núcleo. Después, di si el predicado es } \\
\text { nominal o verbal. }\end{array}$} \\
\hline p. 143 & \multicolumn{2}{|c|}{$\begin{array}{l}\text { - Mi abuela es muy bondadosa. } \\
\text { - El próximo verano iremos de vacaciones a la isla de Sicilia. } \\
\text { - María parece nórdica por su aspecto físico. }\end{array}$} \\
\hline ÍTEM 10 & \multicolumn{2}{|c|}{ Señala de qué tipo es cada uno de los complementos de estas oraciones. } \\
\hline p. 157 & \multicolumn{2}{|c|}{$\begin{array}{l}\text { - Lucas envió un saludo a su madre. } \\
\text { - ¿Te echo azúcar? } \\
\text { - Ya se la he dado. }\end{array}$} \\
\hline
\end{tabular}




\begin{tabular}{|c|c|}
\hline ÍTEM 11 & $\begin{array}{l}\text { Copia los complementos circunstanciales de estas oraciones y señala si son adverbios o } \\
\text { grupos nominales. }\end{array}$ \\
\hline p. 173 & $\begin{array}{l}\text { - El helicóptero aterrizó suavemente. } \\
\text { - iOrdena ahora tu habitación! } \\
\text { - Paula te esperará en la estación del autobús. } \\
\text { - El hombre prehistórico cazaba con armas de piedra. }\end{array}$ \\
\hline ÍTEM 12 & Escribe para cada uno de estos verbos una forma verbal en voz pasiva \\
\hline p. 189 & $\begin{array}{l}\text { - } \text { pelear }> \\
\text { - } \text { seguir }> \\
\text { - } \text { beber }>\end{array}$ \\
\hline ÍTEM 13 & $\begin{array}{l}\text { Relaciona cada una de estas oraciones con el tipo de complemento que aparece subrayado } \\
\text { en su predicado. }\end{array}$ \\
\hline p. 205 & $\begin{array}{l}\text { - Tu primo te escribió una carta. } \\
\text { - América fue descubierta por Colón. } \\
\text { - Yo plancharé la ropa. } \\
\text { - Corta la caja con un cúter. } \\
\text { CC CD Cl CAg }\end{array}$ \\
\hline
\end{tabular}

NOTA: En cada ítem se especifica la página de donde se ha tomado el ejercicio del libro de texto de Edelvives -Proyecto Mundo Agua, Primaria 6 (2009) 